\section{A Static or Dynamic Atom?}

Some writers still contrast the static atom of Lewis and Langmuir with the dynamic atom of Bohr, as if the two alternatives were mutually exclusive. It does not seem to be realised generally that any inconsistency there may have been between them has vanished completely with the publication of Bohr's later views on atomic orbits; speculations about chemical constitution based on the static atom can be translated directly into the language and concəptions of the dynamic atom.

The fundamental idea of Lewis is that non-polar combination consists in the sharing of electrons between atoms in such a way as to complete stable electronic configurations. If the sharing of an electron means the sharing of an orbit, and if the stable electronic configurations are those in which the groups of highest quantum number are completed, as they are in the rare gases: then the Lewis-Langmuir theory, expressed in terms of Bohr's conceptions, states that such compounds are formed when some of the electronic orbits, instead of surrounding one nucleus only, surround both, and therefore help to complete the quantum groups of both atoms. With this principle as a guide, it is merely a matter of linguistic alteration to interpret on the basis of a dynamic atom the conclusions which have been reached on the basis of the static atom.

Of course the question remains whether the theory can be true and whether such shared orbits are possible. This is a matter for quantum theory to decide. My last letter to NATURE on this subject (November 25, I920, vol. I06, p. 408) succeeded in eliciting from Prof. Bohr the first statement of the later and most exciting developments of his theory; perhaps this one will be equally fortunate !

Until the question is settled, it would be waste of time to make the necessary translation, even in a few examples. But it may be well to point out that, if this interpretation of the " sharing of electrons" can be accepted, the task of explaining chemistry according to the Lewis theory will probably be facilitated. For it seems likely that some limitations at present imposed upon the forms of sharing and upon the stable configurations could be removed. So far as I can see, Lewis's principle that only pairs of electrons are shared, and Langmuir's principle (in the original statement) that the stable configuration is always an octet, are based not so much on definite facts as on the need of some guiding principle if speculation is to be limited. The limitations suggested by the identification of stable configurations with the completion, or partial completion, of quantum groups are not exactly those which are usually adopted at present; but once more, while the whole basis of the theory is so uncertain, the attempt to decide the constitution of particular compounds is premature. Norman R. Campbell.

\section{The $Z$ wartebergen and the Wegener Hypothesis.}

CRITICS of the Wegener hypothesis have made a good deal of capital out of the northward deflexion of the folds of the $Z$ wartebergen on approaching the west coast of Africa, but their failure to point out the cause of this deflexion seems to me to lay them open to the charge of advocacy which they so freely lay at Wegener's feet.

The deflexion is produced by the incidence of the chain on a massif of older rocks of the Swaziland System with a core of granite trending north-west. On nearing this resistant axis, the folds bend northwest and then north forming the Cederbergen. Finally, they flatten and die out northwards. 'It is clear that the existence of the granitic axis has interfered with the direct westerly continuation of the folds. The interference, however, is only local, for the Cederbergen do not continue for any distance to the north.

An exactly analogous deflexion occurs in the case of the Armorican folds in Ireland where they impinge on the highly resistant north-easterly trending Wicklow chain with its massive granitic axis. The folds turn north-east in Tipperary as they approach the granite and then north in Kilkenny and Queen's County, where they flatten out and finally disappear. The analogy is very perfect in that the final deflexion from the general trend of the folds is greater than would be brought about by a mere falling into line with the Wicklow chain.

Now, as every one is aware, the interruption along the line of the Wicklow granite does not stop the Armorican folds. They are renewed on the other side of St. George's Channel in southern Wales, where they once more assume their normal direction. If, therefore, we imagine the supposed Atlantic rift valley to have opened up along St. George's Channel, so as to leave Ireland attached to Newfoundland, we may profitably consider what would have happened when one of those irrepressible Germans had come along and announced that it once formed part of the British Isles, basing his argument on the fact that the Irish and Welsh folds, as well as other geological structures, fitted one another when the countries were placed in juxtaposition. The critics would at once have objected that the Armorican folds in Ireland on the west side of the Atlantic turned up northwards before they reached the coast, and therefore could not be regarded as a continuation of those of Wales. It is clear that the objection would have no force in this instance, so one may well ask whether it has any in the actual case of Africa and South America.

\section{Manchester, March 3I.}

W. B. WRIGHT,

\section{Egyptian Water-Clocks.}

PERMIT a brief correction to the paragraph in NATURE of April 7, p. 479, on the casts presented to the Science Museum. The variable divisions of the water-clocks are not for different lengths of day, but compensations for the changes of viscosity of water, over $9^{\circ}$ and $12^{\circ} \mathrm{F}$. respectively. This is proved by the extremes being nearer to the equinoxes than to the solstices, to harmonise with the slow passage of heat through massive temples. Further, the conical form of the clepsydra of I4OO B.C. was to compensate for the greater flow under fuller pressure, the form being a near approach to a portion of a parabola. Thus the variation of pressure was as $I: 3 \cdot 7$, and the water varied as $x: 2 \cdot 9$ to meet this.

\section{W. M. Fi.inders Petrie.}

\section{A Permanent Image on Clear Glass.}

AFTER silvering an ordinary clock glass (about 5 in. diameter) on the convex side, I noticed on removing the wax, with which the concave side had been protected, that a perfectly distinct image of a small child's head had been rendered visible. The image is a photographic "positive."

It occurred to me that the clock glass had possibly been a photographic plate at some earlier time. Presumably it was a plane surface then. In giving the glass the curvature requisite to a clock glass it would be expected that any silver which may have been deposited while the plate was flat would have been disturbed when the glass had been moulded in a molten condition to its present shape. The image, however, is not distorted in the slightest degree. 